\title{
Enhancing the Effect of Aronia Extract on Hyaluronic Acid Synthesis through Liposome Formation
}

\author{
Young Han Youn* \\ Professor, Department of Beauty Care, Sohae College, Gunsan 54116, Korea
}

\section{ABSTRACT}

Background and objective: Aronia melanocarpa, called black chokeberry, is a natural product belonging to the family rosaceae, and is known to contain polyphenolic antioxidants including cyanidin-3-galactoside, cyanidin-3-arabinoside, cyanidin-3-xyloside, and cyanidin-3-glucoside Because of the abundance of anthocyanins, Aronia has been studied to be used in various industries.

Methods: Aronia melanocarpa extract was treated 24 hours a day to RAW 264.7 cells with inflammations induced by LPS. After extracting total RNA, the amount of inflammatory cytokine expression was measured using RT-PCR. After processing the Aronia liposome using Aronia extract and the layer-by-layer electrostatic deposition method in keratinocyte cells at the same time, we checked the synthesis of Hyaluronic acid enhanced through the formation of Aronia liposome using ELISA. Results: The treatment of Aronia extract in inflammation-induced RAW 264.7 cells conducted to check the anti-inflammatory efficacy of Aronia extract inhibited inflammatory cytokines including TLR4, TNF- $\alpha, \mathrm{IL}-1 \beta, \mathrm{COX}-2$, and iNOS and increased the mRNA expression of HAS2 genes related to moisturizing. Based on the anti-inflammatory and moisturizing effect of Aronia extract, the Aronia liposome technology was introduced to Aronia extract to produce Aronia liposome.

Conclusion: The liposome formation of Aronia extract is expected to be used as a functional material in treating various inflammatory skin diseases by controlling the moisture content of the corneocytes by increasing the expression rate of genes associated with the synthesis of hyaluronic acid, while retaining the efficacy of its components.

Keywords: anti-inflammatory, Aronia melanocarpa, inflammatory skin diseases, liposome, moisturizing

\section{Introduction}

As the meaning of beauty in modern society becomes more important, people's interest in skin care has continued to increase. The skin is the first organ that plays a role as a physical barrier to protect the body against various environmental factors, and various environmental stimulations activate the immune system (Chung and Han, 2014).

The activation of the immune system through stimulations such as antigens like lipopolysaccharide (LPS) and allergens, changes in temperature, neural stimulations and ultraviolet rays induce inflammatory cytokines or autoactivate immunocytes or activate other immunocytes, and acti- vated cells release bioactive substances like cytokines (IL-1 $\alpha, \mathrm{IL}-1 \beta$, IL-6) and a chemokine (COX-2), which repeats the pro-inflammatory state and inflammatory reactions (An et al., 2014; Kamsteeg et al., 2010; Lee et al., 2013; Seneschal et al., 2012). Continuous inflammatory reactions turn to chronic inflammations, which can result in P38, c-Jun N-terminal kinases (JNK) and thus the malfunction of mitochondria, and increase the generation of reactive oxygen species (ROSs). In the process of inducing stress within cells, inflammations and direct damage to cells and tissues can be induced, which is known to cause degenerative diseases, cardiovascular diseases and contract dermatitis, one of the chronic inflammatory skin diseases (Aono

Received: July 24, 2020, Revised: August 4, 2020, Accepted: August 7, 2020

First author: Young Han Youn, younhan0716@hanmail.net, (iD) https://orcid.org/0000-0001-5904-3185

*Corresponding author: Young Han Youn, younhan0716@hanmail.net, (D) https://orcid.org/0000-0001-5904-3185 
et al., 1997; Lee et al., 2000; Lee et al., 2010; Lim et al., 2012; Serra et al., 2010; Steenport et al., 2009).

Dermatitis causes the dryness of the skin and itchiness, and the act of scratching the skin further accelerates inflammations and itchiness and breaks down the barrier of the skin, increasing the risk of bacterial infections and causing the early aging of the skin.

Aronia melanocarpa, commonly called black chokeberry, is a berry in the rose family and is widely used in the food industry as a natural coloring substance. Aronia extract reduces the generation of active oxygen and thus the occurrence of inflammations, and is also known to be effective in inhibiting the adhesion of platelets and reducing cohesion. Among various types of berries that have been consumed, Aronia melanocarpa is known as the one with the highest antioxidant activity. Anthocyanins are the most abundant polyphenol antioxidant compound in Aronia melanocarpa and four types of anthocyanins including cyanidin-3-galactoside, cyanidin-3-arabinoside, cyanidin-3-xyloside and cyanidin-3-glucoside are contained in Aronia melanocarpa. The content of anthocyanins is very high $(7.2-8 \mathrm{~g} / \mathrm{kg}$ ) compared to other plants. As anthocyanins and polyphenols in Aronia melanocarpa have strong antioxidant effects and are surprisingly effective for diabetes, the cardiovascular system, cancers, cranial nerves, the skin and allergies, Aronia extract has been utilized in various fields such as foods and cosmetics (Lim et al., 2014; Slimestad et al., 2005; Zheng and Wang, 2003).

Against this backdrop, this study aimed to measure the anti-inflammatory and moisturizing effects of Aronia extract by treating activated macrophages (RAW 264.7) and epithelial keratinocytes (HaCaT) with the extract, and to examine the possibility of utilizing Aronia melanocarpa as a functional raw material for treating inflammatory skin diseases utilizing its anti-inflammatory and skin moisturizing effects by retaining the efficacy of its components and improving the skin absorption rate through liposome formation at the same time.

\section{Research Methods}

\section{Preparation of sample}

The fruits of Aronia melanocarpa used as a raw material to obtain Aronia extract were purchased from Namwon, Jeollanam-do and were extracted with water for the experiment below. The fruits were frozen at $-80{ }^{\circ} \mathrm{C}$ for a day and were freeze-dried and fine Aronia powder was obtained. The Aronia powder was extracted in water at $40{ }^{\circ} \mathrm{C}$ for 24 hours and the extracted water was centrifuged as shown below and pure Aronia extract was obtained using a filter. The pure pre-treated Aronia extract was frozen in a freezer at $-80{ }^{\circ} \mathrm{C}$ for a day and were freeze-dried and an Aronia extract sample in the form of fine powder was obtained and used in the experiment below.

\section{Reagents and equipment}

The reagents used for cell culture including fetal bovine serum (FBS), Antibiotic-Antimycotic, DMEM, Trypsin-EDTA, etc. were purchased from Life Technologies (GibcoR, USA), and the incubator $\left(37{ }^{\circ} \mathrm{C}, 5 \% \mathrm{CO}_{2}\right)$ used for cell culture was purchased from Panasonic (Oska, Japan). Other reagents used in this experiment including lipopolysaccharide (LPS), Crystal Violet, formalin and methanol were purchased from SIGMA (USA).

\section{Cell culture}

The mouse macrophages (RAW 264.7) and epithelial keratinocytes (HaCaT) used in this experiment were obtained from the Korean Cell Line Bank (KCLB 40071, Seoul, Korea), and were cultured in a DMEM medium added with 10\% FBS and 1\% Antibiotic-Antimycotic (10 units $/ \mathrm{mL}$ penicillin, $100 \mu \mathrm{g} / \mathrm{mL}$ sterptomycin, $0.25 \mu \mathrm{g} / \mathrm{mL}$ amphotericin) in the incubator $\left(37{ }^{\circ} \mathrm{C}, 5 \% \mathrm{CO}_{2}\right)$.

\section{Cell viability (\%)}

To determine the cytotoxicity of the sample and the concentration of the extract, a 3-(3,4-dimethyl-thiozolyl-2)-2,5diphenyl tetrazolium bromide (MTT) assay was performed according to the method suggested by Green et al. (1984). 
Cells were seeded in a 24-well plate at the concentration of $1 \times 10^{4}$ cells/well and were cultured for 24 hours. After being treated with the Aronia extract of different concentrations, they were cultured for 24 hours. After that, each well was treated with $10 \mu \mathrm{L}$ of the MTT reagent (Sigma, USA) at the concentration of $1 \mathrm{mg} / \mathrm{mL}$ and was additionally cultured for 4 hours. After completing cell culture, the supernatant liquid was removed from each well, and DMSO (dimethyl sulfoxide, Sigma, USA) was added to each cell to dissolve the produced formazan crystals. Using a microplate reader (Synergy, BioTek, USA), their absorbance was measured at $540 \mathrm{~nm}$.

\section{Measurement of produced nitric oxide}

The amount of nitric oxide (NO) produced above was measured by analyzing $\mathrm{NO}_{2}{ }^{-}$, a stabilized oxide of $\mathrm{NO}$ that exists in the cell culture medium using a Nitrite/Nitrate Assay Kit (GOMA BIO, KOR) with Griess reagent. RAW 264.7 cells were inoculated into the 24-well plate at the concentration of $2 \times 10^{5}$ cells/well and were cultured for 24 hours. After that, the medium was removed and cleaned with FBS and was replaced by a new medium without containing FBS. Cells were treated with $1 \mu \mathrm{g} / \mathrm{mL}$ of LPS and the Aronia extract of different concentrations $(62.5,125$, $250,500 \mu \mathrm{g} / \mathrm{mL}$ ) and were re-cultured for 24 hours. The supernatant liquid was collected from the culture medium and $100 \mu \mathrm{L}$ of the liquid was mixed with $100 \mu \mathrm{L}$ of Griess reagent and was reacted in a 96-well plate for 10 minutes. After that, their absorbance was measured at 540 $\mathrm{nm}$. The concentration of NO within the cell culture medium was calculated by comparing with the standard curve of each concentration of sodium nitrite $\left(\mathrm{NaNO}_{2}\right)$.

\section{UV-A test for inducing hyaluronic acid in $\mathrm{HaCaT}$ cells}

To identify the amount of mRNA expressed by Aronia liposome in $\mathrm{HaCaT}$ cells, RT-PCR was conducted. HaCaT cells were seeded in a 24-well plate at the concentration of $1 \times 10^{4}$ cells/well, and were cultured for 24 hours. After that, the medium was removed and cleaned with FBS. After removing serum in the medium, $1 \mathrm{~mL}$ of FBS was inoculated and UV-A was measured at $6 \mathrm{~J} / \mathrm{cm}^{2}$ using a Bio-Link UV crosslinker (Vilber Lourmat, France). After testing UV-A, the medium was replaced with a serum-free medium and was treated with the Aronia liposome of different concentrations $(50,100$ and $200 \mu \mathrm{g} / \mathrm{mL})$. The cells were cultured for 24 hours additionally. All-trans-retinoic acid (ATRA, sigma) $1 \mu \mathrm{M}$ was used as the positive control group.

\section{Total RNA extraction}

Total RNA was extracted from the inflammation-induced RAW 264.7 cells and HaCaT cells with LPS using TRIZol (Sigma-Aldrich Co., USA) following the instructions of the manufacturer. Reverse transcription polymerase chain reaction (RT-PCR) was performed on the extracted RNA by dissolving it in DEPC (Diethyl Pyrocarbonate) water.

\section{Reverse Transcription Polymerase Chain Reaction (RT-PCR)}

Polymerase chain reaction (PCR) was performed as follows. Using a RT-PCR kit containing DNA polymerase, buffer, dNTP and tracking dye (Bioneer, Korea), cDNA was synthesized from mRNA, and PCR was performed using primers for each gene including IL-6 TNF- $\alpha$, IL- $1 \beta$, COX-2, iNOS and HAS2 for a total of 35 cycles (one cycle was 30 seconds at $94{ }^{\circ} \mathrm{C}, 30$ seconds at $55-62{ }^{\circ} \mathrm{C}$ and 1 minute at $72{ }^{\circ} \mathrm{C}$ ). Electrophoresis was performed on the PCR products in the $1.5 \%$ agarose gel and was observed using a UV transilluminator. For quantitative comparison, they were standardized with beta-actin. The sequence listing of each primer used in this analysis is as shown in Table 1.

\section{Production of Aronia liposome}

Aronia liposome was produced by mixing the 50\% Aronia raw material with the liposome base. According to the recipe in Table 2, each phase was measured and Aronia extract was added to the Hydrogenated Lecithin (0.1-1.0 wt $\%)$ emulsifier to ensure the final concentration is $50 \%$. After that, a magnetic bar was stirred at $500 \mathrm{rpm}$ for $30 \mathrm{~min}$, and high-speed homogenizing was performed at $11,000-15,000 \mathrm{rpm}$ in ice for 5 minutes. Ultrasonic ho- 
Table 1. Sequences of target gene-specific primers used in the RT-PCR

\begin{tabular}{|c|c|c|}
\hline Target gene & & Sequences \\
\hline \multirow{2}{*}{ iNOS } & Forward & 5'-CCCTTCCGAAGTTTCTGGCAGCAGC-3' \\
\hline & Reverse & 5'-GGCTGTCAGAGCCTCGTGGCTTTGG-3' \\
\hline \multirow{2}{*}{$\mathrm{COX}-2$} & Forward & 5'-TTGAAGACCAGGAGTACCGC-3' \\
\hline & Reverse & 5'-GGTACAGTCCCATGACATCG-3' \\
\hline \multirow{2}{*}{ IL-1 $\beta$} & Forward & 5'-AGCCATGGCAGAAGTACCT-3' \\
\hline & Reverse & 5'-CAGCTCTCTTTAGGAAGACAC-3' \\
\hline \multirow{2}{*}{ IL-6 } & Forward & 5'-GTGTTGCCTGCTGCTTCCCTG-3' \\
\hline & Reverse & 5'-CTCTCAGGTATACCTCAAACTCCAA-3' \\
\hline \multirow{2}{*}{ TNF- $\alpha$} & Forward & 5'-TTGACCTCAGCGCTGAGTTG-3' \\
\hline & Reverse & 5'-CCTGTAGCCCACGTCGTAGC-3' \\
\hline \multirow{2}{*}{ HAS2 } & Forward & 5'-GCTACCAGTTTATCCAAACG-3' \\
\hline & Reverse & 5'-GTGACTCATCTGTCTCACCG-3' \\
\hline \multirow{2}{*}{ Beta-actin } & Forward & 5'-TGAAGGTCGGTGTGAACGGATTTCGC-3' \\
\hline & Reverse & 5'-CATGTAGGCCATGAGGTCCACCAC-3' \\
\hline
\end{tabular}

Table 2. Aronia liposome recipe

\begin{tabular}{clc}
\hline Phase & \multicolumn{1}{c}{ INCI name } & Cont. (\%) \\
\hline \multirow{2}{*}{ A } & Water & To 100 \\
& Inulin Lauryl Carbamate & 10.00 \\
& Butylene Glycol & 10.00 \\
& Hydrogenated Lecithin & 5.00 \\
& 1,2-Hexanediol & 2.00 \\
& Chitosan & 0.50 \\
\multirow{2}{*}{ B } & Caprylic/Capric Triglyceride & 10.00 \\
& Polysorbate 60 & 1.00 \\
\hline C & Aronia extract & 50.00 \\
\hline
\end{tabular}

Note. INCI $=$ International Nomenclature Cosmetic Ingredient.

mogenizing was performed at $2 \mathrm{kHz}$ for 3 minutes to produce homogenized Aronia liposome through a total of three stages of homogenization. To produce layer-by-layer electrostatic Aronia liposome, the chitosan biopolymer solution that was produced by treating $\mathrm{pH} 3$ acetate buffer with chitosan to become $0.03 \mathrm{wt} \%$ was mixed with Aronia liposome and was vortexed for 3 minutes.

\section{Skin patch test}

A skin patch test was conducted following the Codes of Ethics based on the Declaration of Helsinki and the Guidelines for the Efficacy Testing of Cosmetics of the
Ministry of Food and Drug Safety, and the approval of the Institutional Review Board (IRB) was obtained (IRB approval No. KDRI-IRB-18246). The method suggested by Frosch and Kligman (1979) was applied to test 30 healthy adults in their 20s-60s (aged 28 years on average) without certain skin diseases and allergies. First, the skin area where a patch was placed was disinfected with $70 \%$ ethanol and the Finn chamber with $15 \mu \mathrm{L}$ of Aronia liposome was placed on the area and was fixed with plaster. The patch was removed after 24 hours, and the tested area was assessed with a naked eye 30 minutes, 48 hours and 72 hours later respectively based on the criteria of the International Contact Dermatitis Research Group (ICDRG) and the Safety Testing Guidelines of the Personal Care Products Council (PCPC). The assessment was performed using the grading system for skin primary irritation test shown in Table 3. Skin reactions were assessed twice and the average irritation index was calculated using Equation 1 and the level of irritation was determined using the following system created based on the Draize Dermal Classification System and the Standard Procedure Dermal Classification System of EPA (Environmental Protection Agency).

$$
\text { Irritation index }=\frac{\sum \text { Irritation score at } 24,48 \text { and } 72 \mathrm{hr}}{\text { Total number of observations }}
$$


Table 3. Grading system for skin primary irritation test

\begin{tabular}{ll}
\hline \multicolumn{1}{c}{ Grade } & \multicolumn{1}{c}{ Description of clinical observation } \\
\hline $0(-)$ & No signs of inflammation, normal skin \\
$0.5( \pm)$ & Doubtful or slight reaction \\
$1(+)$ & Slight erythema \\
$2(++)$ & Moderate erythema with or without partial edema or papules \\
$3(+++)$ & Moderate erythema with diffuse edema \\
$4(++++)$ & Intense erythema with diffuse edema with vesicles \\
\hline
\end{tabular}

\section{Hyaluronic acid (HA) synthesis efficacy}

Cells were seeded in a 24-well plate at the concentration of $1 \times 10^{5}$ cells/well and the plate was washed with a serum-free DMEM after 24 hours. The serum-free DMEM was replaced and the cells were treated with Aronia extract $(200 \mu \mathrm{g} / \mathrm{mL})$ and Aronia liposome (50, 100 and $200 \mu$ $\mathrm{g} / \mathrm{mL}$ ). Dimethyl sulfoxide (DMSO) was set at $0.1 \%$. After 15 minutes, $350 \mu \mathrm{L}$ of the media was removed and after 15 minutes the same amount was removed again. The same amount was removed after 15 minutes once again. The plate was centrifuged at $15,000 \mathrm{x}$ g for 5 minutes and the supernatant liquid was removed. Until the enzyme-linked immunosorbent assay (ELISA) was conducted, the plate was stored at $-20{ }^{\circ} \mathrm{C}$. ELISA was conducted using a HA-ELISA kit (echelon, USA) following the instructions of the manufacturer. All-trans-retinoic acid (ATRA, sigma) $1 \mu \mathrm{M}$ was used as the positive control group.

\section{Statistical analysis}

All the tests except the skin patch test were repeated over five times, and the results were expressed as mean \pm standard deviation (SD). For statistical analysis, one-way analysis of variance (ANOVA) was conducted using SPSS version (IBM, USA) and the significance level was set at $p<.05$.

\section{Results and Discussion}

\section{Cell viability (\%)}

Prior to identifying the effects of Aronia extract on wrinkles, its toxicity on human epithelial keratinocytes (HaCaT

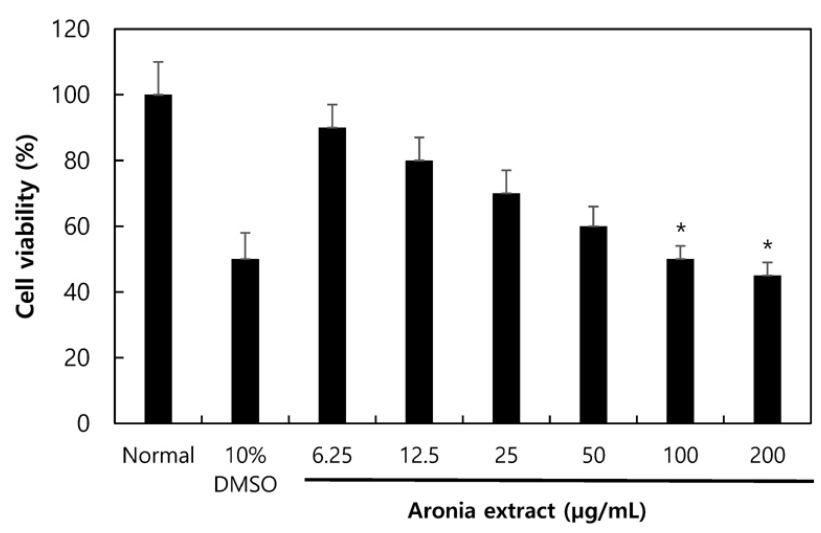

Fig. 1. Cell viability of Aronia extract was determined by MTT assay using HaCaT cell. Error bars represent standard deviations of three independent experiments. ${ }^{*} p<.05$ vs. the normal group.

cell), human skin tissues, and the effective dose for the solvent used in this study were examined using an MTT assay. The HaCaT samples that were diluted to different concentrations $(6.25,12.5,25,50,100$ and $200 \mu \mathrm{g} / \mathrm{mL})$ were treated for 24 hours and the viability of cells was measured. As shown in Fig. 1, the viability of cells at each concentration was found to be as follows compared to the control group ( $1 \mu \mathrm{M}$ of all-trans-retinoic acid treated): $89.24 \%$ at $6.25 \mu \mathrm{g} / \mathrm{m} ; 83.72 \%$ at $12.5 \mu \mathrm{g} / \mathrm{mL} ; 75.21 \%$ at $25 \mu \mathrm{g} / \mathrm{mL} ; 66.42 \%$ at $50 \mu \mathrm{g} / \mathrm{mL} ; 51.74 \%$ at $100 \mu \mathrm{g} / \mathrm{mL}$; and $44.95 \%$ at $200 \mu \mathrm{g} / \mathrm{mL}$. At the concentration of $200 \mu \mathrm{g} / \mathrm{mL}$, toxicity against some corneocytes increased. Although there was no clear toxicity against corneocytes in human skin tissues at a certain concentration of Aronia liposome, it is likely to induce skin irritation at a high concentration.

\section{Amount of NO generated by Aronia extract}

When Lipopolysaccharide (LPS), a Gram-negative endotoxin, is treated to macrophages, LPS shows a pathological response that produces substances such as nitric oxide (NO) and inflammatory cytokines, regulating inflammatory reactions (Yamamoto et al., 1994). NO is produced by inducible nitric oxide synthase (iNOS) in inflammatory reactions, and a proper amount of NO in a health state plays functions such as defense reactions, neural transmission and vascular regulation. However, when the immune system collapses and NO is not regulated, a high concentration of NO is accumulated in the body, which generates toxic 


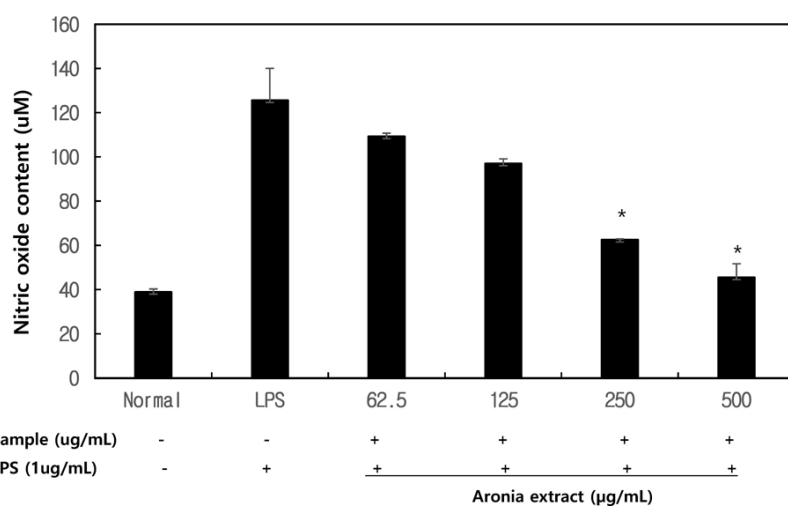

Fig. 2. Effect of Aronia extract on nitric oxide (NO) production of RAW 264.7 cells. RAW 264.7 cells were treated with various concentrations $(62.5,125,250$ and $500 \mu \mathrm{g} / \mathrm{mL})$ of Aronia extract and LPS $(1 \mu \mathrm{g} / \mathrm{mL})$ and then incubated for $24 \mathrm{hr}$. Error bars represent standard deviations of three independent experiments. ${ }^{*} p<.05$ vs the LPS-induced group.

substances like peroxynitrite and nitrogen dioxide and damages DNA. In the process, toxic oxidants accumulate in cells and chronic inflammation causes various types of diseases and inflammatory skin diseases. Therefore, in this study, to examine the anti-inflammatory effects of Aronia extract, RAW 264.7 cells were treated with LPS $(1 \mu \mathrm{g} / \mathrm{mL})$ or the Aronia extract of different concentrations (62.5, 125, 250 and $500 \mu \mathrm{g} / \mathrm{mL}$ ), and after culturing the cells for 24 hours, the amount of NO produced within cells was measured using Griess reagent. The generation of NO strongly increased in the LPS-induced inflammation group with LPS, and showed a concentration-dependent decrease in the Aronia-treated groups (Fig. 2).

\section{Effects of Aronia extract on the expression of iNOS and COX-2 mRNA}

RT-PCR was conducted to examine the effects of Aronia extract on the expression of iNOS and COX-2 in the RAW 264.7 cells stimulated by LPS. The expression of iNOS and COX-2 mRNA strongly increased in the LPS-induced inflammation group by LPS, and showed concentration-dependent decrease in the groups treated with the Aronia extract of different concentrations $(62.5,125,250$ and $500 \mu \mathrm{g} / \mathrm{mL}$; Fig. 3).

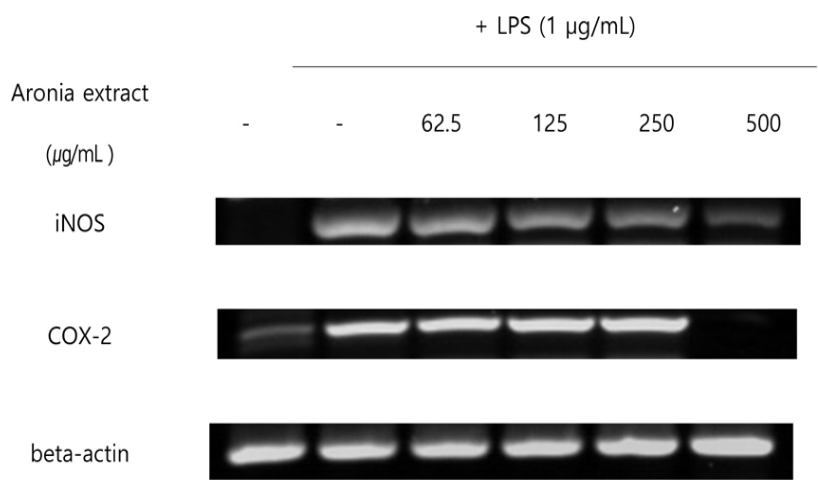

Fig. 3. Effect of Aronia extract on the expression of iNOS and COX-2 in RAW 264.7 cells. RAW 264.7 cells were treated with various concentrations (62.5, 125, 250 and $500 \mu \mathrm{g} / \mathrm{mL})$ of Aronia extract and LPS $(1 \mu \mathrm{g} / \mathrm{mL})$ for $24 \mathrm{hr}$. The levels of mRNA expression of iNOS and COX-2 were quantified by beta-actin for quantitative comparison.

\section{Effects of Aronia extract on the generation of IL-6, $\mathrm{IL}-1 \beta$ and TNF- $\alpha$}

IL-6, IL-1 $\beta$ and TNF- $\alpha$ are known as an inflammatory cytokine released by macrophages and also as an inflammatory mediator that is perceived and activated by toll-like receptor 4 (TLR4), a surface receptor of the RAW 264.7 macrophages stimulated by LPS, causing inflammatory reactions such as fever, edema and pain (Adams and Czuprynski, 1994). In this regard, this study conducted RT-PCR to examine the effects of Aronia extract on the expression of IL- $1 \beta$, IL- 6 and TNF- $\alpha$. To do so, the RAW 264.7 cells stimulated by LPS were treated with the Aronia extract of different concentrations $(62.5,125,250$ and $500 \mu \mathrm{g} / \mathrm{mL}$ ) and were cultured for 24 hours. As a result, the expression of IL-6, IL-1 $\beta$ and TNF- $\alpha$ mRNA strongly increased in the LPS-induced inflammation group by LPS and showed concentration-dependent decrease in the Aronia-treated groups (Fig. 4).

\section{Human skin irritation test of Aronia liposome using skin patch test}

The anti-inflammatory activity of Aronia liposome was tested in vitro, and Aronia liposome was found to have anti-inflammatory effects and thus the level of skin irritation was assessed by placing a patch applied with $20 \mu \mathrm{L}$ of Aronia liposome in the state of liquid on 30 subjects. 


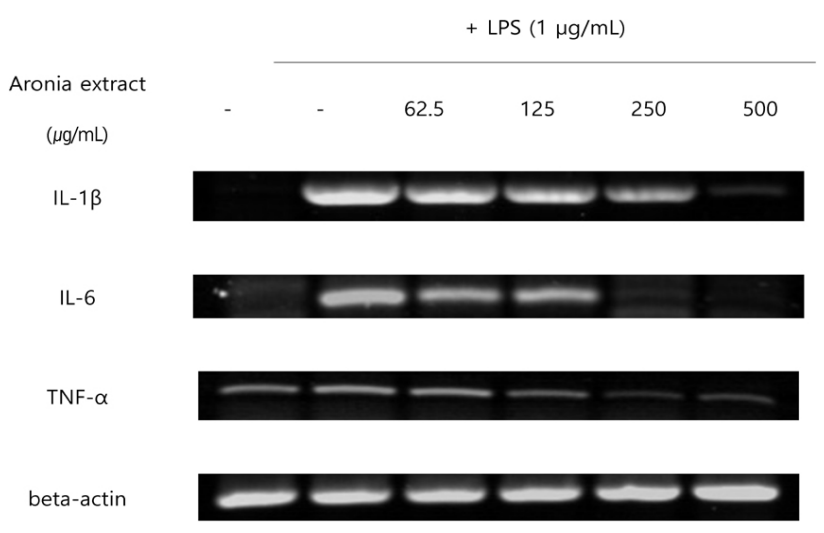

Fig. 4. Effect of Aronia extract on the expression of $\mathrm{IL}-1$ $\beta, \mathrm{IL}-6$ and TNF- $\alpha$ in RAW 264.7 cells. RAW 264.7 cells were treated with various concentrations $(62.5,125,250$ and $500 \mu \mathrm{g} / \mathrm{mL})$ of Aronia extract and LPS $(1 \mu \mathrm{g} / \mathrm{mL})$ for 24 $\mathrm{hr}$. The levels of mRNA expression of IL-1 $\beta$, IL-6 and TNF$\alpha$ were quantified by beta-actin for quantitative comparison.

Table 4. Results of human skin primary irritation test of Aronia liposome

\begin{tabular}{ccc}
\hline Test sample & No. of responder & Reaction grade \\
\hline Aronia liposome & 0 & 0.017 \\
Negative control & 0 & 0 \\
\hline
\end{tabular}

As the reaction grade was 0.017 , all the 30 subjects showed a negative reaction, indicating that Aronia liposome is a hypoallergenic material from the perspective of human skin primary irritation (Table 4).

\section{Hyaluronic acid (HA) synthesis effects}

Through the cell viability test described above, Aronia extract was found to be effective for various inflammatory cytokines at the concentration of $200 \mu \mathrm{g} / \mathrm{mL}$, though a slight toxicity. To identify the synthesis amount of hyaluronic acid (HA) at the concentration compared to the Aronia liposome of different concentrations (50, 100 and $200 \mu \mathrm{g} / \mathrm{mL})$, the enzyme-linked immunosorbent assay (ELISA) was conducted. After treating with the reagent for 24 hours, the amount of HA synthesis was measured using a HA ELISA kit after 15 minutes. In the group treated with the Aronia extract of $200 \mu \mathrm{g} / \mathrm{mL}, 850.52 \mu \mathrm{g} / \mathrm{mL}$ of HA synthesis was produced, and the amount in the groups treated with the Aronia liposome of different concentrations was measured to be $1062.39,1226.30$ and $1078.60 \mu \mathrm{g} / \mathrm{mL}$ re-

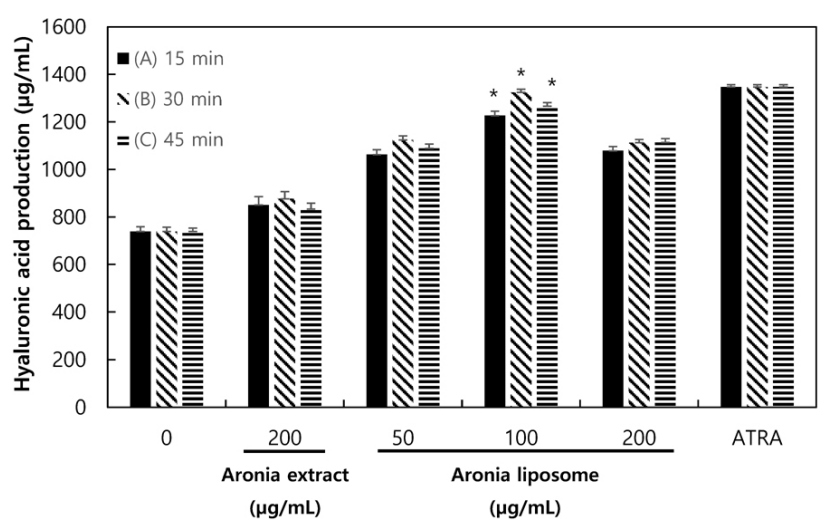

Fig. 5. Effect of Aronia liposome on hyaluronic acid production in $\mathrm{HaCaT}$ cells. $\mathrm{HaCaT}$ cell were treated with Aronia liposome for $15 \mathrm{~min}, 30 \mathrm{~min}, 45 \mathrm{~min}$. Error bars represent standard deviations of three independent experiments. ${ }^{*} p<.05$ vs. the normal group. ATRA = all trans retinoic acid

spectively (Fig. 5). After 30 minutes, the amount in the group treated with Aronia extract of $200 \mu \mathrm{g} / \mathrm{mL}$ was $876.52 \mu \mathrm{g} / \mathrm{mL}$, while the amount in the groups treated with the Aronia liposome of different concentrations was measured to be $1123.75,1324.24$ and $1112.70 \mu \mathrm{g} / \mathrm{mL}$ respectively (Fig. 5). After 45 minutes, the amount in the group treated with Aronia extract of $200 \mu \mathrm{g} / \mathrm{mL}$ was $832.85 \mu \mathrm{g} / \mathrm{mL}$, while the amount in the groups treated with the Aronia liposome of different concentrations was 1088.51, 1266.30 and $1113.60 \mu \mathrm{g} / \mathrm{mL}$ respectively (Fig. 5). The amount of HA synthesis in the sample group after 30 minutes was highest, and when comparing the results between the concentrations of Aronia liposome, the amount of HA synthesis in the $100 \mu \mathrm{g} / \mathrm{mL}$ group was highest, followed by $50 \mu \mathrm{g} / \mathrm{mL}$ and $200 \mu \mathrm{g} / \mathrm{mL}$. The results below indicate that the form of liposome was more effective in synthesizing HA than the extract itself. The group treated with the Aronia liposome of $100 \mu \mathrm{g} / \mathrm{mL}$, compared to the positive control group (all-trans-retinoic acid [ATRA]) showed the HA synthesis of up to $85 \%$, indicating that Aronia is expected to be more effective in the form of liposome in synthesizing HA and thus moisturizing the skin.

\section{Measurement of HAS2 gene expression (RT-PCR)}

The moisturizing effect of Aronia liposome observed in the ELISA test above was examined at the level of mRNA through RT-PCR. The expression of HAS2 gene in the 


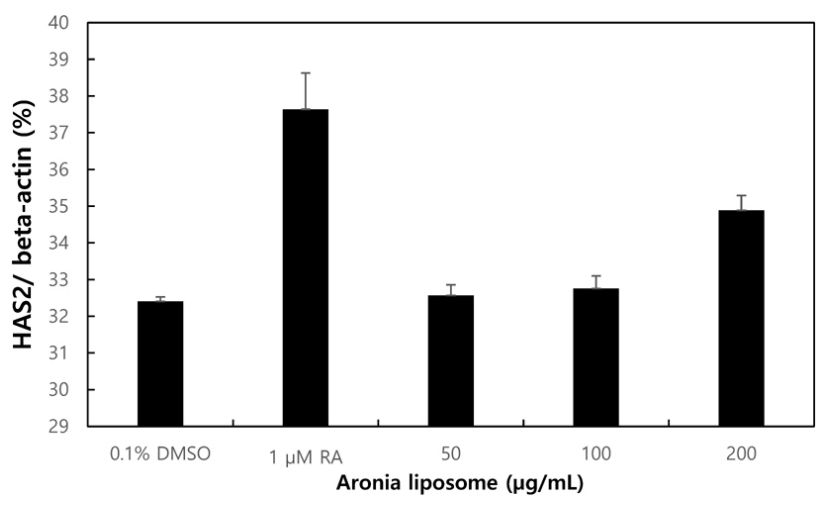

Fig. 6. RT-PCR analysis of epidermal keratin related gene HAS2 showed that the Aronia liposome increased the expression of HAS2 gene. The total RNA was isolated and quantified by beta-actin for quantitative comparison and expressed as a comparison graph. Error bars represent standard deviations of three independent experiments.

groups treated with the Aronia liposome of different concentrations (50, 100 and $200 \mu \mathrm{g} / \mathrm{mL})$ was measured, and all the Aronia liposome-treated groups showed the expression of HAS2 gene. The $200 \mu \mathrm{g} / \mathrm{mL}$ group showed an increase in the expression of HAS2 gene compared to the positive control group (ATRA $1 \mu \mathrm{M}$; Fig. 6). HAS2 gene is an enzyme that produces HA, a protein that transports moisture outside of cells into the cells, and the increase in the expression of HAS2 gene indicates that Aronia liposome is effective in moisturizing the epidermis.

\section{Conclusion}

Inflammatory skin diseases are the results of genetic immune reactions in the skin caused by various external stimulations. When immune reactions are activated in the skin, lymphocytes and macrophages release various inflammatory cytokines to induce immune cells to infiltrate into the epidermis and dermis of the skin. These inflammatory reactions in the skin are accompanied with inflammatory skin diseases such as atopy and adult acne.

This study conducted an in vitro test to examine the moisturizing effect of Aronia extract in the form of liposome. Before the liposome formation of Aronia extract, tests such as ELISA, nitric oxide kit and RT-PCR were conducted to measure the expression of inflammatory cytokines (IL-6,
IL-1 $\beta$ and TNF- $\alpha$ ), the amount of produced NO and the amount of HA synthesis and expression. Aronia extract suppressed inflammatory cytokines and NO concentration-dependently and increased the amount of HA synthesis. This demonstrates that Aronia extract seems to be effective as a natural substance that regulates the reactions of inflammatory cytokines in treating inflammatory skin diseases by moisturizing the skin and regulating inflammations.

Based on the efficacy of Aronia extract, the form of liposome was tested to retain the efficacy and improve its skin absorption rate at the same time. A liposome as an artificial cell membrane comprised of phospholipid can be detected by temperature and light and has gained attention as a bio-friendly drug delivery system. The liposome technology was introduced to Aronia extract and the results of skin irritation and HA synthesis in the groups treated with Aronia liposome were compared with those treated with Aronia extract. The skin irritation level of the groups treated with Aronia liposome was 0.017, lower than 0.02, indicating that Aronia liposome is a non-irritation substance. The amount of HA synthesis and the expression of HAS2 gene that helps HA synthesis were also higher in the groups treated with Aronia liposome than those treated with Aronia extract. In conclusion, introducing the liposome technology to Aronia with anti-inflammatory and moisturizing effects is expected to increase the skin absorption rate and the expression of the gene involved in the synthesis of hyaluronic acid (HA), and thus to increase the content of moisture in corneocytes and to induce moisturizing. Aronia is highly likely to be utilized as a functional raw material for improving various inflammatory skin diseases.

\section{References}

Adams, J.L. and C.J. Czuprynski. 1994. Mycobacterial cell wall components induce the production of TNF- $\alpha$, IL-1, and IL- 6 by bovine monocytes and the murine macrophage cell line RAW 264.7. Microb. Pathog. 16(6):401-411. https://doi.org/10.1006/mpat.1994.1040

An, S.M., H.G. Kim, E.J. Choi, H.H. Hwang, E.S. Lee, J.H. Beak, Y.C. Boo, and J.S. Koh. 2014. Screening for anti-inflammatory activities in extracts from Korean 
herb medicines. J. Soc. Cosmet. Sci. Korea 40(1):95-10 8. https://doi.org/10.15230/SCSK.2014.40.1.95

Aono, K., K. Isobe, K. Kiuchi, Z.H. Fan, M. Ito, A. Takeuchi, M. Miyachi, I. Nakashima, and Y. Nimura. 1997. In vitro and in vivo expression of inducible nitric oxide synthase during experimental endotoxemia: involvement of other cytokines. J. Cell. Biochem. 65(3):349-358. https://doi.o rg/10.1002/(SICI)1097-4644(19970601)65:3<349::AIDJCB5 $>3.0 . \mathrm{CO} ; 2-\mathrm{S}$

Chung, J.Y. and H.S. Han. 2014. The recent trend of percutaneous absorption used in cosmetics. Korean J. Aesthe. Cosmetol. 12(5):597-605.

Frosch, P.J. and A.M. Kligman. 1979. The soap chamber test: A new method for assessing the irritancy of soaps. J. Am. Acad. Dermatol. 1(1):35-41. https://doi.org/10.10 16/s0190-9622(79)70001-6

Green, L.C., J.L. Reade, and C.F. Ware. 1984. Rapid colorimetric assay for cell viability: Application to the quantitation of cytotoxic and growth inhibitory lymphokines. J. Immunol. Methods 70(2):257-268. https://doi.org/10.1 016/0022-1759(84)90190-X.

Kamsteeg, M., P.A.M. Jansen, I.M.J.J. van Vlijmen-Willems, P.E.J. van Erp, D. Rodijk-Olthuis, P.G. van der Valk, T. Feuth, P.L.J.M. Zeeuwen, and J. Schalkwijk. 2010. Molecular diagnostics of psoriasis, atopic dermatitis, allergic contact dermatitis and irritant contact dermatitis. Br. J. Dermatol. 162(3):568-578. https://doi.org/10.1111 /j.1365-2133.2009.09547.x

Lee, E.G., B.M. Mickle-Kawar, and R.M Gallucci. 2013. IL-6 deficiency exacerbates skin inflammation in a murine model of irritant dermatitis. J. Immunotoxicol. 10(2):192-200. https://doi.org/10.3109/1547691X.2012. 707700

Lee, H.M., J.H. Choi, C.S. Choi, S.J. Hwang, and H.L. Lee. 2000. Expression of MMP-9 and TIMP-1 in the nasal mucosa of allergic rhinitis. Korean J. Otolaryngol. 43:604-609.

Lee, J.T., K.J. Woo, and T.K. Kwon. 2010. Effect of sulforaphane on LPS-induced matrix metalloproteinase-9 (MMP-9) expression. J. Life Sci. 20(2):275-280. https:// doi.org/10.5352/JLS.2010.20.2.275
Lim, J.D., H.S. Cha, M.G. Choung, R.N. Choi, D.J. Choi, and A.R. Youn. 2014. Antioxidant activities of acidic ethanol extract and the anthocyanin rich fraction from Aronia melanocarpa. Korean J. Food Cook. Sci. 30(5):573-578. https://doi.org/10.9724/kfcs.2014.30.5

Lim, J.W., Y.J. Cho, D.H. Lee, B.C. Jung, H.S. Kang, T.J. Kim, K.J. Rhee, T.U. Kim, and Y.S. Kim. 2012. Upregulation of MMP is mediated by MEK1 activation during differentiation of monocyte into macrophage. J. Exp. Biomed. Sci. 18(2):104-111.

Seneschal, J., E. Kubica, L. Boursault, J. Stokkermans, C. Labreze, B. Milpied, K. Ezzedine, A. Taïeb. 2012. Exogenous inflammatory acne due to combined application of cosmetic and facial rubbing. Dermatology 224(3):221-223. https://doi.org/10.1159/000338694

Serra, R., A.G. Al-Saidi, N. Angelov, and S. Nares. 2010. Suppression of LPS-induced matrix-metalloproteinase responses in macrophages exposed to phenytoin and its metabolite, 5-(p-hydroxyphenyl-), 5-phenylhydantoin. J. Inflamm. 7:48. https://doi.org/10.1186/1476-9255-7-48

Slimestad, R., K. Torskangerpoll, H.S. Nateland, T. Johannessen, and N.H. Giske. 2005. Flavonoids from black chokeberries, Aronia melanocarpa. J. Food Compos. Anal. 18(1):61-68. https://doi.org/10.1016/j.jfca.2003.1 2.003

Steenport, M., K.M. Faisal Khan, B. Du, S.E. Barnhard, A.J. Dannenberg, and D. J. Falcone. 2009. Matrix metalloproteinase (MMP)-1 and MMP-3 induce macrophage MMP-9: Evidence for the role of TNF- $\alpha$ and cyclooxygenase-2. J. Immunol. 183(12):8119-8127. https://doi.org/10.4049/jimmunol.0901925

Yamamoto, Y., P. He, T.W. Klein, and H. Friedman. 1994. Endotoxin induced cytotoxicity of macrophages is due to apoptosis caused by nitric oxide production. J. Endotoxin Res. 1(3):181-187. https://doi.org/10.1177/0 96805199400100307

Zheng, W. and S.Y. Wang. 2003. Oxygen radical absorbing capacity of phenolics in blueberries, cranberries, chokeberries, and lingonberries. J. Agric. Food Chem. 51(2): 502-509. https://doi.org/10.1021/jf020728u 